\title{
Leisure mobility styles in Swiss conurbations: construction and empirical analysis
}

\author{
Timo Ohnmacht $\cdot$ Konrad Götz $\cdot$ Helmut Schad
}

Published online: 1 March 2009

(C) Springer Science+Business Media, LLC. 2009

\begin{abstract}
Leisure travel is the most difficult travel purpose to analyse due to the lack of fixed spatial and temporal referents and the consequent flexibility in patterns. This paper addresses lifestyles, social influence, and the travellers' social networks, issues that have proved valuable for travel behaviour research in confronting the complexity of leisure travel. An approach for constructing leisure mobility styles, based on orientations towards leisure and mobility, will be presented first and then the hypotheses that transport behaviour can be better explained through analysis of leisure mobility styles will be tested. Multivariate analysis reveals that the leisure mobility style group makes a significant contribution towards clarifying variance for the activities 'Visiting friends and relatives', 'Travel participation', 'Mode choice', and 'Travel distance for leisure'. The use of leisure mobility styles is most useful for developing practical intervention pointers where the ingroup homogeneity of lifestyle should be addressed in greater detail.
\end{abstract}

Keywords Mobility orientations · Lifestyles · Leisure mobility styles · Urban mobility $\cdot$ Social networks $\cdot$ Leisure travel

\section{Lifestyles, social networks, and social influence}

Transportation researchers' goal is to understand, describe and model the travel distances, mode of transport and destination choices that people make during their everyday lives. Over the last few decades, the motives and determinants of individual travel behaviour have been analysed from different perspectives. While the main approaches explore

T. Ohnmacht $(\bowtie) \cdot$ H. Schad

Lucerne University of Applied Sciences and Arts, Lucerne, Switzerland

e-mail: timo.ohnmacht@hslu.ch

H. Schad

e-mail: helmut.schad@hslu.ch

K. Götz

Institute for Social-Ecological Research Frankfurt/Main, Frankfurt am Main, Germany

e-mail: goetz@isoe.de 
personal mobility in relation to objective constraints, such as the built environment (Schad et al. 2008), space (Koppelman 1983), travellers' socio-demographic characteristics (Pas 1994), and the general costs of travel (Gunn 2001), travel behaviour research adds several sociologically driven perspectives to the analysis, for example, role patterns (Hanson and Pratt 1995; Kwan 1999; Root et al. 2000; Schwanen et al. 2007, 2008), household interactions (Gliebe and Koppelman 2002; Scott and Kanaroglou 2002), time budgets (Banerjee et al. 2007), activity planning (Miller and Roorda 2003), and mobility biographies (Scheiner 2007). Other approaches to understanding travel behaviour from a sociological point of view are lifestyle (Ohnmacht et al. 2008b; Collantes and Mokhtarian 2007; Schwanen et al. 2007; Götz et al. 2003; Kitamura 1988; Salomon 1983), social networks (Ohnmacht 2009; Axhausen 2008; Ohnmacht et al. 2008a; Axhausen 2007), and their associated social influence (Páez and Scott 2007). These approaches have proved valuable for transportation research mainly in the field of leisure travel, which is the most important travel segment and has the highest share of road transport.

Leisure travel accounts for a substantial part of the increase in vehicle kilometres travelled in recent years. In detail, comparing the results from the 2005 Swiss Microcensus on Travel Behaviour to the year 1984 (the first comparable microcensus), there is an increase of 15 per cent in person-kilometres travelled in leisure time (ARE/BfS 2007). Moreover, the 2005 Swiss Microcensus on Travel Behaviour showed that 45 per cent of person-kilometres travelled in Switzerland are due to leisure time activities (in total, 43 billion person-kilometres) (ARE/BfS 2007). For the year 2005, Ohnmacht et al. (2008b, pp. 29-61) have shown that, based on the Swiss Microcensus on Travel Behaviour, 26 per cent of all trips in Switzerland are leisure trips within an urban area comprising a number of cities, large towns and larger urban areas that, through population growth and physical expansion, have merged to form one continuous urban and industrially developed area that came to be termed as 'conurbation'; 62 per cent of all trips in leisure travel start and end within the same conurbation. 23 per cent of the volume of travel in Switzerland is produced by trips that start and end in the same conurbation during leisure time. This corresponds to 21.9 thousand million out of a total 95.5 thousand million person-kilometres travelled (PKT) in Switzerland. As a result, leisure travel contributes to high emissions and is related to high energy consumption.

In transportation research, it is often assumed that travel is a pre-determined demand derived from various factors. In the case of leisure travel, however, this travel purpose is not affected as strongly by necessities as, for instance, work-related transport. In comparison to other travel purposes, leisure travel is more difficult to analyse due to the lack of fixed spatial and temporal referents and the consequent flexibility in patterns (Schlich et al. 2004). As a result, leisure travel is perceived as the most difficult segment for determining influences. A very detailed understanding of its complex structures is important before suggesting approaches to a sustainable urban traffic system. The complexity of leisure travel implies important conceptual and methodological challenges. Lifestyles, social networks, and social influence are particularly important categories with regard to leisure travel (Dugundji et al. 2008). Leisure travel is mainly about being with other people (Larsen et al. 2006). In Switzerland, 17.4 per cent (1.82 billion PKT) of all leisure trips within conurbations are for the purpose: 'Visiting friends and relatives' (Ohnmacht et al. 2008c). Considering that other leisure activities, such as 'Walking outdoors' (walking, hiking, strolling in the city; 27.5 per cent, 1.32 billion PKT), 'Restaurant' (23.5 per cent, 1.48 billion PKT), 'Active Sports' (10.7 percent, 1.24 billion PKT), and 'Culture Events' (5.6 per cent, 0.6 billion PKT) are also undertaken jointly with others to a high percentage, the relevance of social influences on leisure travel becomes clear. 
The paper pursues four main objectives in researching leisure travel behaviour with regard to interrelationships between lifestyles, social networks, and social influences: Firstly, developing 'Leisure mobility style' groups based on people's various orientations with regard to leisure activities, and their attitudes toward differing modes of transport. Secondly, our hypothesis is that there is a correlation between leisure mobility style groups and various parameters of travel, such as trip rate, modal-split, trip purposes and travel distances, both for leisure and in general. Thirdly, as a scope of interpretation, the empirical results will be discussed with regard to how the lifestyles affect decision-making. We argue that lifestyles are highly influenced by in-group homogeneity (Páez and Scott 2007; Dugundji and Walker 2005). Fourthly, the discussion of social influences on the mobility style groups will be connected to pointers of practical interventions towards sustainable travel behaviour. We used the Swiss population living in conurbations as defined by the Swiss Federal Office for Spatial Development (ARE/BfS 2003) for our analysis.

The remainder of this paper is organised into six sections: In Section "Theoretical backgrounds and previous research", we present relevant topics of discussion in transportation research, sociology, and mobility studies concerning the use of lifestyles in general and leisure mobility styles in particular as a research category. This is followed by a brief discussion on data collection in Section "The data". In Section "Constructing leisure mobility styles", the methods applied are presented along with information on how to construct and interpret mobility style in leisure time for people living in Swiss conurbations. Section "Leisure mobility styles and their relationship to travel behaviour" considers how to model the relationship between leisure mobility styles and indicators of travel behaviour using multivariate methods. The results that concern recent themes in transportation studies of social networks and social influence and practical interventions (Section "Practical interventions") will be discussed. Finally a conclusion will be provided (Section "Concluding remarks").

\section{Theoretical backgrounds and previous research}

The theoretical background of mobility styles rests on a three-dimensional definition of the term. Firstly, spatial mobility is defined as the manoeuvrability of individuals and objects within a physical geographical space that includes coupling constraints in time and space (see also the concept of capability constraint Hägerstrand 1970). Secondly, socio-spatial mobility is defined as the availability of opportunities to fulfil needs such as places to eat, sleep, work, undergo training, enjoy life, and so forth, within a social space. Thirdly, sociocultural mobility represents social positioning (Jahn and Wehling 1998). Hence, we argue that mobility is connected with attitudes, values, and orientations. For orientations, the underlying assumption is that there is always a symbolic dimension to where and how one moves, which in turn demonstrates one's affinity to a particular social milieu. Therefore, in order to consider all three mobility dimensions in travel research, travel behaviour needs to be operationalised as a derived demand, one, as a means of satisfying personal needs, and two, as a dimension of social positioning in the form of lifestyle orientations and social influence derived from the travellers' social networks.

Social stratification and lifestyles

Lifestyles can be understood as latent constructs comprising individuals' attitudes, values, and orientations; they are expressed, for instance, in differing tastes (Bourdieu 
1984) and thus influence everyday behaviour and expressions of taste, which may then be related to daily practices. The debate about lifestyles is rooted in sociologically driven theories of increasingly differentiated and individualised ways of living, which lead to augmented forms of social stratification and differentiation in modern societies (Giddens 2001). In opposition to early discussions on lifestyle, we do not assume any antagonism between the approaches of social inequality (vertical differentiation) and pluralisation (horizontal differentiation). We assume the resulting variability of inequality patterns to be closely related to forms of mobility and travel (see Ohnmacht et al. 2009, for a discussion on mobility and inequality structure). In general, social stratification and pluralisation refers to unequally distributed resources, e.g., wealth, status, prestige, or power, within a social system (Erikson and Goldthorpe 1992), as well as the differing social positions or styles of everyday life. Our understanding of social stratification is based on the placement of individuals within a 'social space'. Thus, social space implies two dimensions:

Firstly, it contains a vertical dimension, by which we mean differences in sociodemographic and socio-economic characteristics, such as gender, age, income, educational level, and so forth. Secondly, social stratification is distinguished by horizontal dimensions, by which we mean different attitudes, opinions, tastes, and values (Bourdieu 1984; Bergman 1998). In this typical 'ideal' understanding, the two axes are considered orthogonal. However, it should be stressed that these two axes are often seen as interdependent (cf. Konietzka 1995).

These theories hold that one's position within social space is closely related to the dimension of lifestyle (for data on Switzerland see Lamprecht and Stamm 1998). Against this background, the lifestyle concept concerning orientation towards mobility and leisure activities is termed 'leisure mobility styles', by which we mean a specified area of lifestyle. This assumes that in addition to the classical factors that explain an individual's travel behaviour, i.e., income, age, gender, etc., various other personal characteristics, i.e., attitudes, opinions, and values, also determine travel behaviour. In practical research terms, this means that methods used in attitudinal and lifestyle research are coupled with methods of researching travel behaviour. Of interest is how the concept of leisure mobility styles based on attitudes, values, and orientations is related to the domain of concrete mobility preferences and (leisure) travel behaviour.

The main advantage of the mobility style approach as applied to leisure time is to group individuals in a meaningful way that embraces lifestyle attributes related to mobility and leisure activities. Methodologically speaking, meaningful groups based on leisure and mobility orientations are formed by applying factor and cluster analyses. The objective in the empirical part of the paper is to demonstrate how to construct leisure mobility style groups for citizens living in Swiss conurbations. Furthermore, travel behaviour research has been mostly concerned with the vertical dimension of social space (age, gender, etc.), whereas this research and related research attempt to add as well the horizontal dimension. In our view, leisure travel behaviour is to some extent a function of a leisure mobility lifestyle. We hypothesise that leisure mobility styles are significantly related to habitual practices and are thus a part of expressing lifestyle, which may also be manifested in travel behaviour. We test the assumption that transport behaviour in leisure time and in general can be better explained by analysing lifestyle-specific orientations, background attitudes, and motivations. 
Discussion of the empirical examinations of lifestyle with regard to social networks and social influence

Past travel behaviour research and social scientists' mobilities studies did not take account of the social structures of the travellers. In recent times, however, research in the area of transport studies, geography, and sociology has focused on the interplay between modes of transport, information and communication technology (ICT) and the structure, social influence, and spatial dispersion of social networks. Expanding our understanding of travel behaviour, this research on social networks and travel has revealed new methods for collecting social network data and for modelling social networks as a means of researching travel behaviour (Axhausen 2008; Ohnmacht et al. 2008a; Carrasco et al. 2006; Larsen et al. 2006). By definition, social activity-travel research studies the link between an individual's social activities and social contacts with regard to their effect on travel behaviour, e.g., the travel purpose 'Visiting friends and relatives'. More concretely, this research branch examines how travel and communication behaviour is affected by the socio-spatial dimension, i.e., social network geography or social influence.

Transport is a means of social integration and thus contributes significantly to the lifestyle domain. Thus, according to Páez and Scott (2007, pp. 662) "the next step towards a more refined understanding of travel behaviour will take as starting point the proposition that human beings are social animals". A vivid example of lifestyle-oriented travel was the trendy Dorian Gray disco at Frankfurt Airport, frequented on an international scale in the 1970 s by members of high society, even by plane. The other extreme is the local pub around the corner, from which one can walk home. This pub does not become one's 'local' just because it is conveniently located, but rather because the right people go there.

Lifestyles can be coupled with the concept of social influence as discussed by Páez and Scott (2007), who illustrate the importance of social influence on telecommuting, such as peer pressure and the need to belong. Moreover, in terms of in-group homogeneity of personal social space, social actors are assumed to be socialised in large measure within the same lifestyle group (Plickert et al. 2007). Páez and Scott (2007) use an empirical analysis of adopters of telecommuting to show that individuals pay attention to adopting decisions made by others in their social sphere (see also Bamberg and Möser 2007). In the case of social influence, the decision-making process for travelling is one where individuals are attracted to alternatives that seem attractive to other people with whom they share some affinity. While the social influence approach described in Páez and Scott (2007) is based on direct interagent action, the lifestyle classification applied in this concept understands lifestyle-specific orientations, background attitudes, and motivations as contextual effects (see Páez 2006, for a recent discussion) or as aggregated agent interdependencies (Dugundji and Walker 2005). People in similar lifestyle groups tend to respond in a systematic way. Bamberg et al. (2007) revealed that mode choice is correlated with personal norms arising from social contexts. Leisure mobility style-groups are assumed to be homogeneous because the groups are made up of people with the same orientations, background attitudes, and motivations. Likewise, they are assumed to be heterogeneous in relation to other lifestyle groups due to dissonance in relation to their preferences.

The lifestyle approach presented in this paper has the advantage that it does not impose the elaborate data requirements that a direct interaction approach would need. The differences between the two approaches is the same as between an interaction perspective and a group heterogeneity perspective. Our bridge hypothesis (Esser 1998) is that lifestyle clusters understood as contextual segments are a way of at least partially capturing social influence effects. A further approach to incorporate social influence is by means of 'area 
effects', as discussed by Dugundji and Walker (2005). In their approach, Dugundji and Walker (2005) deal with anonymous networks to research interdependencies among decision-makers. In detail, these researchers consider aggregate agent interdependencies, networks where other individuals are not necessarily recognised (in contrast to the named networks of Páez and Scott (2007)). This allows the average field effect to be considered, rather than the actions of specific individuals, in order to arrive at the social influence effect.

Whereas Dugundji and Walker (2005) introduce field effects from a geographical perspective, dealing in fact with geographical areas, we argue that the lifestyle clusters described in this paper could provide a way to investigate field effects in social space instead. The scope of interpretation for the empirical results of the lifestyle groups in terms of travel behaviour and measures of interventions includes another way of applying the clustering method that would permit a more direct treatment of potential inter-agent interactions and can thus be linked to measures of practical interventions.

\section{Empirical findings on travel and lifestyles}

Over the past few years, lifestyle and attitudinal research have been identified as important additional approaches for explaining travel behaviour, particularly with regard to leisure mobility.

In the early 1980s, transportation researchers in North America began to investigate the role of lifestyle. Salomon and Ben-Akiva (1983) utilised the concept of lifestyles to estimate models for the combinations of chosen modes and shopping destinations. The results demonstrated that lifestyle groups account for taste variations better than the classical explanatory factors found in the vertical dimension of social stratification. Salomon (1983) investigated lifestyle groups by applying cluster analysis. Lifestyles are regarded as the basis for long-term decisions influencing travel behaviour, such as residential location, housing type, automobile ownership, and mode to work (Salomon 1983, p. 293). Kitamura (1988) researched the lifestyles of US citizens based on consumer expenditure patterns and life cycle stages to start a debate on their interconnectedness to travel behaviour. This early branch of research has the disadvantage of not defining lifestyle according to mobility and activity orientations. Instead, Salomon and Ben-Akiva (1983), Salomon (1983), and Kitamura (1988) defined lifestyle groups by using individual and household items as proxy variables along the dimension of life-cycle stages, such as age, employment, sex, income, car ownership, and licence holding.

More recent literature has worked with attitudinal and psychometric variables to empirically explore the determinants of individuals' subjective assessments of their mobility (Collantes and Mokhtarian 2007). These researchers ascertained that personality traits, travel-related attitudes, and lifestyle characteristics signicantly influence such assessments. Schwanen et al. (2007) investigated attitudes toward travel and land use and choice of residential neighbourhood. They showed explicitly how self-selection towards location decisions is based on attitudes. Walker and Li (2007) proved these findings of how, in terms of travel-relevant, long-term decisions, lifestyle is a key element in the decision of where to live.

In the German-speaking world, the use of mobility styles was first applied by the Institute for Social-Ecological Research, Frankfurt am Main, with a special focus on reducing the environmental impact of leisure and tourism travel (for information on leisure mobility see Götz et al. 2003, 1997). One of the research goals was to estimate the environmental effect of travel behaviour in a way that is lifestyle-specific. For these 
purposes, a $\mathrm{CO}_{2}$ emissions model was combined with the travel behaviour data of the lifestyle groups. The researchers concluded that, for the German sample, a lifestyle-specific grouping is helpful in understanding the complexity and disparity of mobility orientations. Based on their five types of mobility styles, they were able to develop group-specific measures and recommendations that may influence behaviour in the interests of sustainability.

A further German study on mobility styles, also concentrating on mobility and leisure activity, was undertaken for four neighbourhoods in Cologne. Lanzendorf (2002) observed a correlation between mobility styles and participation in travel and car use for leisure travel at the weekend. Moreover, by using multivariate analysis, it was shown that mobility styles explain people's participation in travel for differing leisure purposes and the distance travelled by car. Bamberg and Schmidt (1994) applied the theory of planned behaviour to explain people's choice of travel mode. The theory of planned behaviour is an approach for researching the link between attitudes and actual behaviour (Ajzen 1980). According to this approach, a specific behaviour results from the complex interplay of attitude, subjective norm, and motivation. In fact, Bamberg and Schmidt (1994) were able to predict students' intention to travel to their university lectures by car or bicycle by applying structural equation models. They explained nearly 80 per cent of the variance in people's intention to use a car or bicycle by referring to attitude, subjective norm, and motivation. Despite showing how mode choice, amongst other things, is affected by attitudes towards much-frequented destinations, they did not focus on activity and destination choice. Scheiner and Holz-Rau (2007) discussed the theoretical considerations of the links between life situation, lifestyle, choice of residential location and travel behaviour. For the survey area of Cologne, their results indicated that when testing for socio-economic factors, lifestyles admittedly appear to have a significant influence on mode choice, while the strength of impact on travel behaviour of life styles remains rather limited. For Switzerland, Lücking and Meyrat-Schlee (1994) worked with a simplified lifestyle approach. They defined lifestyles according to socio-demographic characteristics in combination with information on the course of peoples' lives. For leisure travel in urban areas, they found that lifestyles have a small but significant effect on mode choice.

Clearly the concept of lifestyle has been included in the conceptual and empirical research framework to explain travel behaviour in a variety of research projects, although with variations in the way the concept of lifestyle is operationalised. In fact, a problem that may be encountered is that these differing approaches vary in the way they operationalise the concept of lifestyle. One problem that we encountered is that in many empirical frameworks, the concept of lifestyles was operationalised using various proxy variables taken from a real-life situation. One can argue that such operationalisations do not capture the dimension of lifestyle properly. Kitamura (1988, p. 184) ascertained early that the "adequacy of the standard approach in lifestyle analysis (i.e., identification of sample segments using available socio-economic measurements) must be critically examined. The variation in lifestyle that can be accounted for by adopting such a segmentation scheme may be limited. Analytical methods need to be developed to account for individuality or idiosyncrasy in lifestyle." Socio-economic and life-cycle stages data may indeed be seen as a proxy for indicating lifestyles, but we argue that lifestyles or mobility styles can best be captured by rating statements on motivations and orientations concerning differing aspects of mobility and leisure activities. The former concept neglects the potential of people's orientations, values, and attitudes regarding mobility and travel as measurement variables for the latent construct of lifestyle. The effect of attitudinal issues and lifestyle on travel behaviour has not been adequately taken into account, for example, the perceived value of 
a particular means of transport in terms of its commodiousness (e.g., reading a book on a train) or as a symbol of a socio-cultural position. Moreover, the approach of using mobility styles explicitly with orientations towards leisure time has seldom been applied in current research. As far as the authors are aware, this approach has not yet been carried out in Switzerland. Therefore, this study is the first to report on this geographical region in the literature. In the following sections, we focus on the Swiss empirical findings and present the results against the background of recent findings in the field of transportation research concerning social networks and social influence.

\section{The data}

The first aim of the project was to define statements of value, orientation, and opinion related to leisure and travel behaviour. A second aim was to develop a study design to define the population for which we wished to construct leisure mobility styles. One objective of the project was to develop measures leading to sustainable leisure travel. We argue that the biggest potential for helping people move around in a more sustainable way within conurbations exists when alternatives to car travel are available.

We applied the conurbation definition developed by the Swiss Federal Offices of Spatial Development (ARE) and Statistic (BfS) to Switzerland for the framework of our study (ARE/BfS 2003). Finally, a questionnaire was developed and tested for conurbations in the German- and French-speaking parts of Switzerland. The survey was carried out by a commercial institute. A representative survey was collected from June to July 2007 $\left(\mathrm{CATI}^{1}\right)$. A total of 823 respondents were interviewed (response rate: 26 percent). The research was restricted to Swiss conurbation populations aged 18 and older and living in the French- and German-speaking parts (see Ohnmacht et al. 2008b, for more details).

The questionnaire consisted of six parts: the first was a detailed list of regular leisure pursuits based on an item list developed by Opaschowski for Germany (BAT-Freizeitforschungsinstitut 2004). This list was slightly altered, adapted and validated for Switzerland by three Swiss experts (see items in Table 1). It operationalises statements on values, orientations, and opinions with regard to leisure activities, both indoor and outdoor. Secondly, we used the same detailed list to establish preferred leisure activities. For the third section, an item list concerning mobility orientation was developed, constructed on the basis of items previously used in transportation research (Götz et al. 2003). This gave rise to four groups of items concerning orientation towards cars, public transport, bicycles, walking, and multi-modality (see list in Table 2). Fourth, we examined the trips of the interviewees, who were asked to report all trips made on the preceding day, and compared the results with those of other travel surveys (mainly ARE/BfS 2007). Fifth, an individual personal survey was included, covering various socio-demographic characteristics and household data. The sixth section deals with access to and availability of transport modes.

\section{Constructing leisure mobility styles}

In the following section, we discuss how to achieve an adequate grouping of individuals based on their attitudes. We argue that leisure travel can be explained more effectively in relation to basic orientations and attitudes of social groups. This was operationalised on the

${ }^{1}$ Computer Assisted Telephone Interview. 
Table 1 Twelve extracted factors for leisure orientations

\begin{tabular}{|c|c|c|c|c|c|c|c|c|c|c|c|c|}
\hline Leisure activities & F1 & $\mathrm{F} 2$ & F3 & $\mathrm{F} 4$ & F5 & F6 & F7 & F8 & F9 & F10 & F11 & F12 \\
\hline Spending time with kin & 9 & -7 & 32 & -8 & 4 & 2 & 11 & 4 & 12 & 55 & 9 & -8 \\
\hline Spending time with friends & 11 & 30 & 53 & -8 & -2 & -12 & 14 & -6 & 27 & 26 & 9 & -1 \\
\hline Meeting $\mathrm{p}$ & 4 & 39 & 46 & -22 & 2 & -8 & 27 & -2 & 20 & 24 & 12 & 2 \\
\hline Partying & 6 & 71 & 21 & 11 & -1 & 2 & 12 & 10 & 4 & 1 & -9 & 0 \\
\hline Gardening & 3 & -5 & 9 & -15 & 6 & 7 & 71 & 1 & 5 & 15 & 1 & 14 \\
\hline Weekend home & 25 & 1 & 0 & 10 & 12 & -1 & 57 & 15 & 16 & -3 & -16 & -1 \\
\hline Home improven & 0 & 15 & 0 & 13 & 6 & 7 & 62 & -11 & -11 & 18 & 5 & 9 \\
\hline Board ga & 5 & 12 & -1 & 9 & -12 & 14 & 17 & 4 & 2 & 68 & -1 & 5 \\
\hline Making music & 0 & 19 & 6 & -9 & 21 & 37 & 7 & 6 & 1 & -4 & 6 & 54 \\
\hline Having a rest/being la & -3 & 4 & 12 & 14 & 2 & -3 & -1 & -10 & 75 & 12 & 3 & -1 \\
\hline Personal care & -2 & 13 & 2 & -2 & 3 & -3 & 11 & 23 & 65 & -4 & 12 & 9 \\
\hline Watching TV, DVD & -21 & 4 & 25 & 46 & -22 & 15 & 9 & 12 & 18 & -20 & 18 & -13 \\
\hline Listening to music & 15 & 10 & 42 & 12 & 12 & -7 & -17 & -10 & 21 & -1 & 47 & 32 \\
\hline List & -1 & 5 & 7 & -7 & 12 & 6 & -1 & 11 & 9 & 4 & 74 & 2 \\
\hline Newspapers, magaz & 7 & 2 & 13 & -11 & 19 & 14 & -5 & -5 & 15 & 8 & 29 & -45 \\
\hline Books & -6 & -9 & 6 & -29 & 52 & 9 & -3 & 13 & 38 & 11 & -3 & -1 \\
\hline Computer $\mathrm{g}$ & 0 & -3 & 19 & 71 & -2 & -11 & -6 & 0 & 2 & 22 & -8 & 7 \\
\hline Surfing in $t$ & 29 & 6 & 65 & 22 & 14 & 1 & -6 & 13 & -15 & 7 & -6 & -2 \\
\hline Private phoni & -4 & 9 & 67 & 4 & 1 & 15 & 5 & 21 & 7 & 1 & 4 & -1 \\
\hline Attendin & 1 & 56 & -23 & 19 & 6 & 20 & 10 & 10 & -6 & 17 & 27 & -12 \\
\hline Cinema & 23 & 14 & 26 & 6 & 20 & -12 & -13 & 45 & 4 & -3 & 5 & -4 \\
\hline Opera, theatre & 6 & 6 & -4 & -3 & 74 & 11 & 12 & -4 & 1 & -11 & 12 & -5 \\
\hline Rock, pop, jaz & 27 & 52 & 12 & -5 & 16 & -3 & -6 & 9 & 3 & -1 & 17 & 24 \\
\hline Museum, art & -5 & -1 & 10 & -8 & 79 & -4 & 15 & 8 & -5 & 1 & 6 & 0 \\
\hline Furthe & 34 & 23 & 15 & 2 & 35 & 8 & -19 & 15 & 7 & 30 & -17 & 13 \\
\hline Bar, restaurant, café & -4 & 43 & 14 & 17 & 7 & -3 & -5 & 21 & 27 & 8 & 8 & -26 \\
\hline Dancing, disco, $\mathrm{cl}$ & 11 & 51 & 22 & 10 & -17 & -1 & -13 & 26 & 11 & -5 & 1 & 31 \\
\hline Church service, cemetery & -4 & -11 & 0 & -2 & -4 & 81 & 6 & -4 & 1 & 5 & 10 & -5 \\
\hline Doing community work & 15 & 3 & 5 & -1 & 7 & 81 & 1 & 7 & 4 & 0 & -5 & 4 \\
\hline $\mathrm{Clu}$ & 20 & 24 & 1 & -12 & 13 & 52 & 6 & 0 & -25 & 20 & 5 & -3 \\
\hline Cycling, mountai & 54 & -24 & 4 & -10 & -1 & 1 & 10 & 23 & -3 & 21 & 16 & -6 \\
\hline Hiking & 20 & -13 & 3 & -44 & 28 & 2 & 38 & 2 & 12 & 14 & 6 & -13 \\
\hline Swimming & 11 & 11 & 8 & -10 & -9 & 0 & 11 & 61 & -18 & 16 & 15 & 8 \\
\hline Sauna, spa & 12 & 12 & -7 & 4 & 15 & 15 & -10 & 59 & 21 & 10 & -15 & 8 \\
\hline Cruising by & 9 & 21 & -8 & 67 & -8 & -5 & 10 & 5 & 11 & -4 & 3 & 7 \\
\hline Pleasure trips on we & 19 & 19 & 11 & -29 & 16 & -10 & 20 & 36 & 12 & 32 & 5 & -8 \\
\hline Shopping, malling & -10 & 7 & 25 & 27 & -3 & 1 & 6 & 53 & 13 & -12 & 17 & -6 \\
\hline Attending sports events & 38 & 23 & -16 & 26 & -22 & 6 & -7 & 10 & 1 & 12 & 43 & -16 \\
\hline Leisure parks & -3 & 4 & -9 & 31 & 12 & 4 & 25 & 23 & -7 & 43 & 35 & 13 \\
\hline Winter sports & 70 & 9 & 2 & -1 & -5 & 15 & 6 & 0 & -5 & 8 & 8 & -2 \\
\hline Outdoor activities & 56 & 22 & -1 & -11 & 15 & -5 & 21 & 0 & -20 & -19 & -3 & 7 \\
\hline Other sports activities & 67 & 8 & 16 & 5 & 0 & 7 & 3 & 7 & 9 & 3 & -8 & 1 \\
\hline
\end{tabular}


Table 1 continued

\begin{tabular}{lllllllllllll}
\hline Leisure activities & F1 & F2 & F3 & F4 & F5 & F6 & F7 & F8 & F9 & F10 & F11 & F12 \\
\hline Pets & -1 & -4 & -1 & 18 & -6 & -10 & 26 & -1 & 20 & 15 & 14 & $\mathbf{5 9}$
\end{tabular}

Question: How important are the following leisure activities to you?

Scale from 4 to 1 ; (4) very important, (3) important, (2) less important, (1) not important, $n=823$ rotated component matrix, factor loadings multiplied by 100 , factor loadings above $+/-.40$ printed in bold type

Table 2 Nine extracted factors for mobility orientations

\begin{tabular}{lllllllllll}
\hline Mobility orientations & F1 & F2 & F3 & F4 & F5 & F6 & F7 & F8 & F9 \\
\hline
\end{tabular}

Car

I feel independent with a car

Without a car I can't handle my daily life

Without a car one is seen as irrelevant in society

Most recent cars are too big, fast, and heavy

People who know what life is all about have a car

A bit of risk is part of the attraction of driving

Leisure activities are not possible without a car

If possible, I use public transport instead of a car

People who drive a lot should be made to pay more for environmental damages

Cars are the best way to get around

Public Transport (PT)

PT is good for relaxation

I prefer PT in order to get in touch with others

I prefer PT because I can do other things while travelling (phoning, etc.)

PT is too inflexible for me

Transfer to other trains, buses is annoying

It bothers me that I am confronted with awkward people on PT

For my situation I'd like to see a better PT system

Too much money is invested in PT

Bicycle

A bicycle for me stands for freedom and independence

Bicycles are the best way of getting around

Bicycle riders behave inconsiderately in road traffic

I feel in danger on a bicycle

I sometimes ride across the red traffic light on my $\begin{array}{lllllllllllll}-11 & 5 & 25 & -21 & -14 & 31 & 11 & -7 & -51\end{array}$ bicycle

For me, riding a bicycle is exhausting and inconvenient

For me, a bicycle is the ideal mode of transport as I -12

$$
\begin{array}{llllllll}
9 & \mathbf{- 6 9} & -4 & 0 & -17 & 22 & 14 & -9
\end{array}
$$

$$
\begin{array}{rrrrrrrrr}
\mathbf{7 1} & -3 & 3 & -19 & -8 & 6 & -18 & -2 & 5 \\
\mathbf{6 9} & -17 & -8 & -16 & -1 & -6 & 7 & 27 & -3 \\
6 & -5 & -5 & -7 & 2 & \mathbf{5 9} & 20 & 2 & -10 \\
-5 & 12 & 16 & 14 & 15 & -8 & \mathbf{6 5} & 11 & -2 \\
\mathbf{5 2} & -15 & -2 & -1 & 4 & 36 & 0 & 1 & -1 \\
11 & 7 & 19 & 14 & 0 & \mathbf{5 5} & -36 & 2 & 0 \\
72 & -16 & -9 & 4 & -7 & 9 & -5 & 8 & 2 \\
\mathbf{- 4 7} & 23 & 32 & 26 & 13 & 0 & 17 & -5 & 10 \\
-26 & 20 & 5 & 14 & -4 & -1 & \mathbf{6 5} & -2 & -5 \\
& & & & & & & & \\
\mathbf{7 1} & -8 & -19 & -19 & -15 & 9 & -14 & -2 & 13 \\
& & & & & & & & \\
1 & 8 & 21 & \mathbf{7 0} & 10 & -13 & 9 & -5 & -5 \\
-24 & 17 & 1 & \mathbf{6 9} & -1 & 19 & 8 & 5 & 14 \\
-34 & 5 & 29 & 53 & 6 & 1 & 13 & -3 & -1 \\
& & & & & & & & \\
29 & -4 & -14 & -27 & -7 & 6 & -3 & \mathbf{6 4} & 13 \\
22 & -4 & -6 & -\mathbf{4 8} & -24 & 22 & 2 & 31 & 14 \\
-2 & -1 & -1 & \mathbf{- 4 9} & -4 & 28 & -6 & 18 & \mathbf{4 2}
\end{array}
$$$$
\begin{array}{rrrrrrrrr}
6 & -1 & 8 & 3 & -3 & 0 & 7 & 86 & 4
\end{array}
$$$$
\begin{array}{lllllllll}
7 & -7 & -22 & -10 & -6 & 57 & -17 & 2 & 1
\end{array}
$$$$
\begin{array}{lllllllll}
-2 & 77 & 5 & 5 & 5 & -2 & 3 & 2 & -2
\end{array}
$$$$
\begin{array}{lllllllll}
-19 & 76 & -1 & 10 & -2 & 12 & 17 & -10 & 2
\end{array}
$$$$
\begin{array}{rrrrrrrrr}
5 & -1 & 6 & -11 & 10 & -5 & -2 & 7 & 71
\end{array}
$$$$
\begin{array}{lllllllll}
14 & -36 & 7 & -5 & 5 & 26 & 38 & -13 & 41
\end{array}
$$$$
4-69-4-17-22-14-9-25
$$
can handle short destinations 
Table 2 continued

\begin{tabular}{|c|c|c|c|c|c|c|c|c|c|}
\hline Mobility orientations & F1 & $\mathrm{F} 2$ & $\mathrm{~F} 3$ & $\mathrm{~F} 4$ & F5 & F6 & F7 & F8 & F9 \\
\hline \multicolumn{10}{|l|}{ Walking } \\
\hline I like walking & 0 & 7 & 12 & 18 & 79 & -2 & 17 & 1 & 7 \\
\hline Walking is too slow & 20 & 2 & -2 & -5 & -74 & 11 & 10 & 11 & -3 \\
\hline I like to walk greater distances in general & -12 & 7 & 14 & 1 & 82 & 8 & 7 & -1 & 7 \\
\hline $\begin{array}{l}\text { I only enjoy walking in a leisure context (hiking, } \\
\text { etc.) }\end{array}$ & 33 & 6 & -7 & 6 & -17 & -6 & 5 & 13 & 22 \\
\hline \multicolumn{10}{|l|}{ Multi-modality } \\
\hline $\begin{array}{l}\text { I'm not fixed on a distinct mode of } \\
\text { transport; my mode choice depends on the situation }\end{array}$ & -6 & 8 & 79 & 0 & 11 & -2 & 8 & 2 & -15 \\
\hline $\begin{array}{l}\text { It goes without saying that I choose my mode of } \\
\text { transport depending on the situation }\end{array}$ & -17 & 4 & 77 & 15 & 8 & 0 & 0 & 4 & -4 \\
\hline $\begin{array}{l}\text { It's important to me to combine public transport } \\
\text { and bicycle }\end{array}$ & -19 & 48 & 36 & 9 & -5 & -6 & 19 & -11 & 23 \\
\hline $\begin{array}{l}\text { It's perfect that you can combine various modes of } \\
\text { transport }\end{array}$ & -10 & 6 & 65 & 27 & 13 & -16 & 9 & -9 & 21 \\
\hline
\end{tabular}

Question: Do you agree with following statements?

Scale from 4 to 1 ; (4) fully agree, (3) agree, (2) disagree, (1) fully disagree, $n=823$ rotated component matrix, factor loadings multiplied by 100 , factor loadings above $+/-.40$ printed in bold type

basis of preferred leisure activities and mobility-orientation. To construct the leisure mobility styles, the orientation items for mobility and leisure time were selected from the questionnaire, followed by factor analysis, and, finally cluster analysis.

For factor analysis, VARIMAX rotation with Kaiser criteria was used (see Backhaus et al. 2006, for methodological issues). Overall, we extracted 13 factors from 43 leisure activities, which explain the 55.5 per cent of the variance (see Table 1). By the same method, nine factors were extracted for mobility orientations from the 33 items on mode attributes, which explain the 57.2 per cent of the variance as represented in Table 2.

A cluster analysis was conducted on the basis of the 21 factor-variables (12 leisure orientation factors and nine mobility orientation factors, see Table 3). The task of a cluster analysis is to generate clusters (groups of cases) that are relatively homogeneous within a cluster and heterogeneous in relation to other clusters (see Backhaus et al. 2006, for methodological issues). The Ward's algorithm in combination with the K-means algorithm was used. This orientation-based clustering led to the identification of four groups. The decision for four groups was made after comparing the results with various other cluster solutions. Four groups were judged to be the best solution to allow for sufficient scope for interpretation.

The four leisure mobility styles were described according to their cluster centres (Table 4) and their socio-economic and socio-spatial characteristics (Table 5). In order to clarify their cluster-specific differentiation in terms of their social situation, we gave the leisure mobility styles characteristic names:

- Sporty Types (SPO): showing an affinity for bicycles (28 per cent)

- Fun and Distraction Seekers (FUN): showing an affinity for cars (16 per cent)

- Culture-Oriented (CUL): multi-modal and critical of cars (33 per cent)

- Neighbourly Home-Lovers (HOME): showing an affinity for cars and public transport (22 per cent) 
Table 3 Interpretation of extracted factors-Leisure \& mobility orientations

\begin{tabular}{llll}
\hline Factors with leisure orientations (lo) & Factors with mobility orientations (mo) \\
\hline & Interpretation & & Interpretation \\
$\mathrm{F} 1_{l o}$ & Active sports & $\mathrm{F} 1_{m o}$ & Attraction of car \\
$\mathrm{F} 2_{l o}$ & Fun \& entertainment & $\mathrm{F} 2_{m o}$ & Attraction of bicycles \\
$\mathrm{F} 3_{l o}$ & Active networking with ICT and face-to-face & $\mathrm{F} 3_{m o}$ & Multi-modality \\
$\mathrm{F} 4_{l o}$ & Escapism with media & $\mathrm{F} 4_{m o}$ & Attraction of public transport \\
$\mathrm{F} 5_{l o}$ & High culture & $\mathrm{F} 5_{m o}$ & Attraction of walking \\
$\mathrm{F} 6_{l o}$ & Volunteer work & $\mathrm{F} 6_{m o}$ & Cars benefit social integration \\
$\mathrm{F} 7_{l o}$ & House, garden, home improvement (DIY) & $\mathrm{F} 7_{m o}$ & Critical of cars \\
$\mathrm{F} 8_{l o}$ & Wellness and fitness & $\mathrm{F} 8_{m o}$ & Critical of public transport \\
$\mathrm{F} 9_{l o}$ & Relaxation & $\mathrm{F} 9_{m o}$ & Frightened by traffic \\
$\mathrm{F} 10_{l o}$ & Leisure with family & & \\
$\mathrm{F} 11_{l o}$ & Listening to music & & \\
$\mathrm{F} 12_{l o}$ & Leisure at home & & \\
\hline
\end{tabular}

These groups were differentiated by characteristics on the basis of statistically significant deviation from the mean overall cases. Certain relationships between personal and household characteristics, local information, and availability of transport modes concerning the leisure mobility styles will be mentioned in the following descriptions.

\section{The Sporty Types (SPO)}

As the name implies, The Sporty Types (SPO) appreciate active sports such as cycling, winter sports, and hiking, as well as passive sports such as visiting a sports event. Members of this group enjoy using the Internet. They are not into passive forms of leisure activity such as idle relaxation or watching television. The bicycle is a popular form of transport, but this type also favours the car for long-distant journeys. Its members dislike walking, which seems inconsistent with their sporty and dynamic lifestyle, but they consider walking too slow. Representatives of this group are more frequently men (58 per cent) and are more likely to be found in the younger groups aged 18 to 29 years (33.5 per cent). A relatively large share (42.8 per cent), compared to the average, live in households with children. Furthermore, The Sporty Types (SPO) are found more often in the Germanspeaking parts of Switzerland (86.7 per cent). This type occurs more often in high-income household groups (CHF 6,000 to 10,000, 36.4 per cent), and is rarely interested in high culture, such as opera and theatre. Furthermore, most of the households have at least one bicycle.

\section{The Fun and Distraction Seekers (FUN)}

The Fun and Distraction Seekers (FUN) are somewhat younger and technically minded (18-29 years, 48.5 per cent). They are oriented towards entertainment electronics, such as personal computers, and television. They may also be characterised by a tendency to spend their leisure time in idle relaxation. Hanging out with friends is an important means of maintaining their social networks. They enjoy partying or going to restaurants, pubs, bars, 
Table 4 Cluster centres of leisure mobility styles

SPO FUN CUL HOME

\begin{tabular}{|c|c|c|c|c|c|}
\hline \multicolumn{6}{|c|}{ Factors with leisure orientations } \\
\hline $\mathrm{F} 1$ & Active sports & .33 & -.12 & .21 & -.63 \\
\hline $\mathrm{F} 2$ & Fun \& entertainment & -.18 & .14 & -.14 & .33 \\
\hline $\mathrm{F} 3$ & Active networking with ICT and face-to-face & .09 & .38 & .09 & -.51 \\
\hline $\mathrm{F} 4$ & Escapism with media & -.27 & .89 & -.44 & .36 \\
\hline F5 & High culture & -.66 & -.42 & .70 & .07 \\
\hline F6 & Volunteer work & .01 & -.29 & .04 & .13 \\
\hline F7 & House, garden, home improvement & -.17 & -.13 & -.13 & .50 \\
\hline F8 & Wellness and fitness & .23 & -.58 & -.12 & .30 \\
\hline F9 & Relaxation & -.59 & .41 & .26 & .05 \\
\hline F10 & Leisure with family & .13 & -.22 & -.11 & .17 \\
\hline F11 & Listening to music & -.01 & -.58 & .13 & .22 \\
\hline F12 & Leisure at home & -.31 & .14 & .21 & -.03 \\
\hline \multicolumn{6}{|c|}{ Factors with mobility orientations } \\
\hline $\mathrm{F} 1$ & Attraction of car & -.05 & .16 & -.25 & .32 \\
\hline $\mathrm{F} 2$ & Attraction of bicycless & .50 & -.37 & .12 & -.53 \\
\hline $\mathrm{F} 3$ & Multi-modality & -.09 & -.21 & .03 & .21 \\
\hline $\mathrm{F} 4$ & Attraction of public transport & .01 & -.89 & .09 & .47 \\
\hline F5 & Attraction of walking & -.52 & -.56 & .55 & .19 \\
\hline F6 & Cars benefit social integration & -.41 & .45 & -.16 & .42 \\
\hline F7 & Car criticsm & -.08 & -.58 & .52 & -.28 \\
\hline F8 & Critical of car & .02 & .06 & .16 & -.31 \\
\hline F9 & Critical of public transport & -.20 & -.09 & -.09 & .46 \\
\hline
\end{tabular}

Bold type: High deviations of factor mean from cluster centre

Note: $\mathrm{SPO}=$ The Sporty Types; FUN $=$ The Fun and Distraction Seekers; CUL $=$ The Culture-Oriented; HOME $=$ The Neighbourly Home-Lovers

or cafés in the company of friends. Moreover, this type has a very strong affinity to the car and shuns other modes of transport. For them, the car is not just for locomotion but is also a form of material prestige and a symbol of social integration. A disproportionately large number live in the French-speaking part of Switzerland, if we consider the FUN group's share of the Swiss population (31.6 per cent). Furthermore, this type frequently lives in bigger cities with more than 200,000 citizens (61.9 per cent). Per household, they have fewer bicycles and are less likely to make regular use of public transport than the average.

\section{The Culture-Oriented (CUL)}

A distinctive feature of The Culture-Oriented (CUL) group is their high educational levels (tertiary educational level of 36.6 per cent). Representatives of this group enjoy various leisure activities: playing and listening to music, visiting exhibitions or galleries, reading books, and acquiring additional education. Moreover, this group is actively committed to community work. Representatives of this group mainly favour walking, biking, and the use of public transport to participate in leisure activities. Their criticism of the car stems from 
Table 5 Leisure mobility styles by personal and household characteristics, local information, and availability of transportation modes in percent

\begin{tabular}{|c|c|c|c|c|c|}
\hline & SPO & FUN & CUL & HOME & Total \\
\hline \multicolumn{6}{|c|}{ Personal and household characteristics } \\
\hline Men & 57.7 & 59.0 & 43.1 & 44.6 & 50.0 \\
\hline \multicolumn{6}{|l|}{ Age } \\
\hline $18-29$ years & 33.5 & 48.9 & 15.2 & 18.4 & 26.4 \\
\hline $30-59$ years & 57.7 & 41.9 & 73.3 & 54.8 & 59.8 \\
\hline $60+$ years & 8.8 & 9.2 & 11.4 & 26.8 & 13.8 \\
\hline \multicolumn{6}{|l|}{ Net household income (per month) } \\
\hline Below CHF 2,000 & 1.2 & 4.7 & 1.9 & 2.9 & 2.4 \\
\hline CHF $2,000-4,000$ & 11.0 & 12.8 & 8.5 & 11.6 & 10.6 \\
\hline CHF $4,001-6,000$ & 12.7 & 18.6 & 22.7 & 29.5 & 20.8 \\
\hline CHF $6,001-10,000$ & 36.4 & 18.1 & 37.1 & 28.5 & 31.9 \\
\hline Above CHF 10,000 & 27.7 & 19.6 & 21.6 & 11.2 & 20.6 \\
\hline \multicolumn{6}{|l|}{ Educational attainment } \\
\hline Primary & 11.1 & 21.1 & 5.0 & 14.0 & 11.8 \\
\hline Secondary & 65.6 & 57.7 & 58.4 & 68.8 & 62.1 \\
\hline Tertiary & 23.3 & 21.2 & 36.6 & 17.3 & 26.1 \\
\hline Persons living in household & 22.6 & 31.8 & 18.4 & 18.3 & 21.7 \\
\hline Person lives in a partnership & 75.1 & 62.4 & 71.7 & 74.3 & 71.7 \\
\hline Child under 18 in household & 42.3 & 32.6 & 27.7 & 31.5 & 33.4 \\
\hline \multicolumn{6}{|l|}{ Local information } \\
\hline German-speaking part & 86.7 & 69.4 & 73.8 & 67.9 & 75.3 \\
\hline \multicolumn{6}{|l|}{ Size of conurbation } \\
\hline $200,000+$ & 47.4 & 61.9 & 57.4 & 52.9 & 54.3 \\
\hline $50,000-199,999$ & 39.9 & 23.9 & 33.2 & 33.8 & 33.7 \\
\hline Up to 49,999 & 12.7 & 14.2 & 9.4 & 13.3 & 11.9 \\
\hline Lives in conurbation centre & 36.6 & 44.7 & 45.7 & 32.4 & 39.9 \\
\hline \multicolumn{6}{|l|}{ Availability of transport modes } \\
\hline Bicycle in household & 96.2 & 71.8 & 89.4 & 72.8 & 84.7 \\
\hline Car in household & 84.0 & 85.5 & 71.7 & 78.1 & 78.8 \\
\hline Car-sharing member & 2.7 & 3.7 & 3.6 & 0.6 & 2.7 \\
\hline Subscription to public transport & 65.6 & 45.9 & 77.4 & 60.5 & 65.3 \\
\hline
\end{tabular}

All the cross-tables are significant on the 0.05 level (chi-square-test)

Reading example: 84 percent of 'The Sporty Types' (SPO) have a car in their households

Note $:$ SPO = The Sporty Types; FUN = The Fun and Distraction Seekers; CUL = The Culture-Oriented; HOME $=$ The Neighbourly Home-Lovers

ecological considerations. This group includes a disproportionately high number of women (56.9 per cent). Its members are more likely to be middle-aged ( 30 to 59 years, 73.3 perent). Households with children occur to a lesser extent than average (27.7 per cent). Furthermore, this type is found slightly more often in the French-speaking part of Switzerland (45.7 per cent). They have more bicycles per household than average and make regular use of public transport more often. 
The Neighbourly Home-Lovers (HOME)

The Neighbourly Home-Lovers may best be typified as tradition-oriented (see Plöger 2006). This type of person values family and a sense of security, and is mainly characterised by their domestic and neighbourly orientation. Within this group, we also find a gender division. Firstly, while men prefer to engage in gardening and home improvement in their leisure time, women like to indulge in shopping as a leisure time activity. Secondly, while men's preferred mode of transport is the car, which they rate as a sign of social integration, women prefer to use public transport. Both men and women dislike the idea of cycling and consider it exhausting, inconvenient, and dangerous, a fact that is also reflected in the lower number of bicycles per household. Overall, this type is characterised by a high degree of sociability. Their favourite pastimes are visiting restaurants and playing cards in the company of friends. Over-represented in this group are women (55.4 per cent) and older people $(60+$ years, 26.8 per cent), and people on a middle income (CHF 4,0006,000, 29.5 per month). Furthermore, they are more likely to be found in the Frenchspeaking part of Switzerland (67.6 per cent).

\section{Leisure mobility styles and their relationship to travel behaviour}

We are interested in how these four groups relate to empirical observations on travel behaviour. We will test our hypotheses of a relationship between mobility orientations and travel behaviour with the assistance of multivariate analysis. This allows us to analyse whether leisure mobility orientations affect travel behaviour, whilst controlling for other factors such as socio-demography, availability of means of transport, and local information.

The multivariate analysis has two parts. Firstly, various binominal logit models were calculated for participation in travel and leisure activities. For continuous variables, we applied an ordinary least square (OLS) regression analysis for mode share on trips and travel distance, both in percentages and travel distances for leisure in kilometres.

The results of the binominal logit analysis indicate that the Sporty Types (SPO) leisure mobility style is the only significant contributor to participation in travel (see Table 6). The odds ratio indicates that this type has a high likelihood of participation in travel. In fact, the odds for participation in travel change by a factor of 2.8 for Sporty Types. Furthermore, the likelihood that the same SPO type will participate in the leisure activity 'Visiting friends and relatives' decreases by a factor of 0.5 . This means that Sporty Types undertake less travel to visit friends and relatives as compared to Neighbourly Home-Lovers (HOME). For the travel purpose 'Visiting friends and relatives', a car in the household has a negative effect on participation, and the SPO type, a style that is characterised by relatively high levels of car ownership and use, also has a negative and significant coefficient. This finding echoes recent findings by Farber and Páez (in press, pp. 4) in time-use research that suggests a negative effect of auto mobility in social activity participation and duration.

In all other models, the contribution of leisure mobility styles to travel behaviour turn out to be insignificant, which indicates that classic predictors, such as income, local information and availability of modes of transport, are more relevant (Table 6).

The regression analysis was applied by using the backward stepwise method to generate best-fit models (see Table 7). In all models, leisure mobility styles were found to be major contributors, especially for car-share against trips and travel distances. The model for leisure travel distance has a rather poorly adjusted $R^{2}$ value. Nevertheless, the residuals are normally distributed and we controlled for multicollinearity. In contrast, the models to 


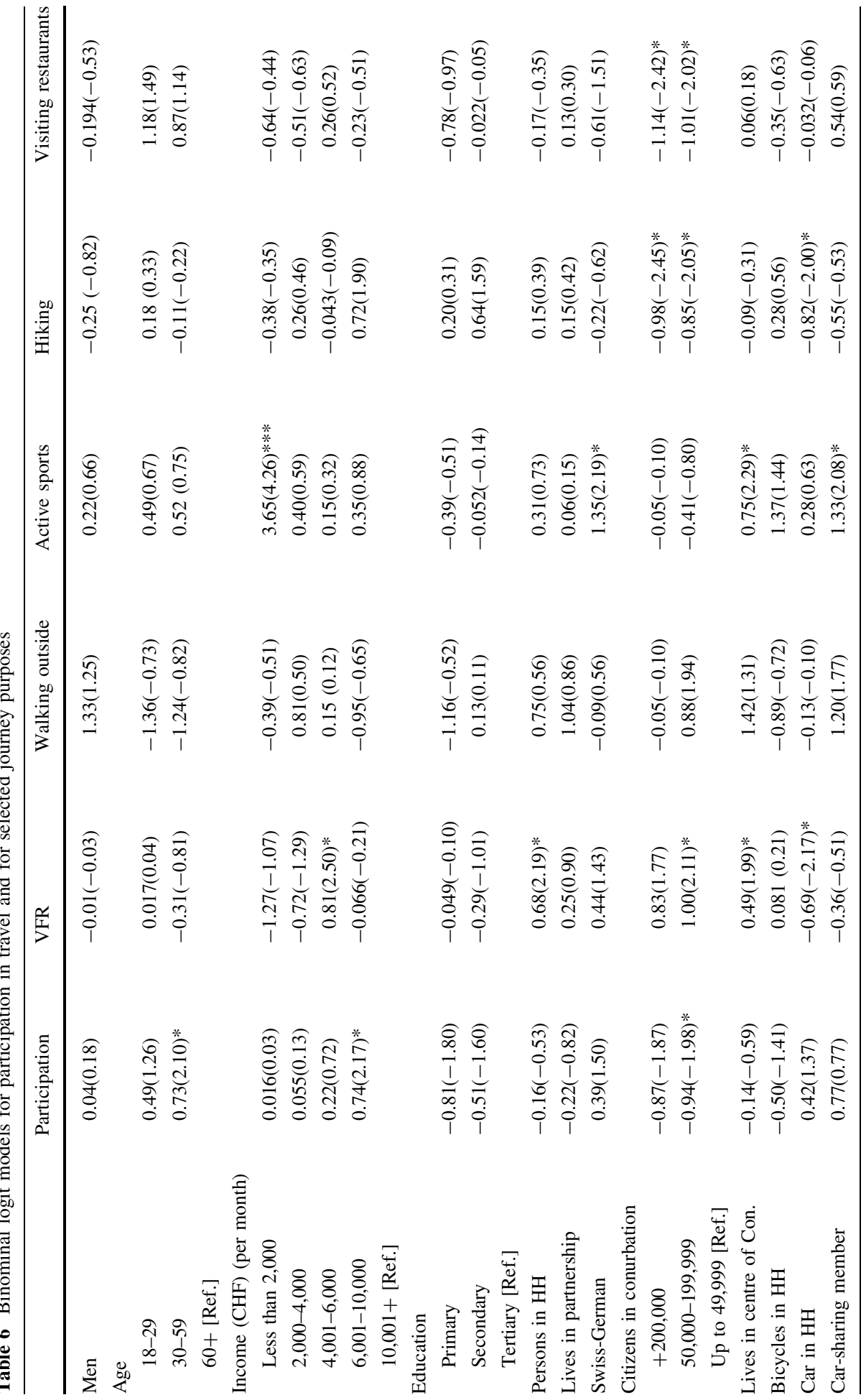




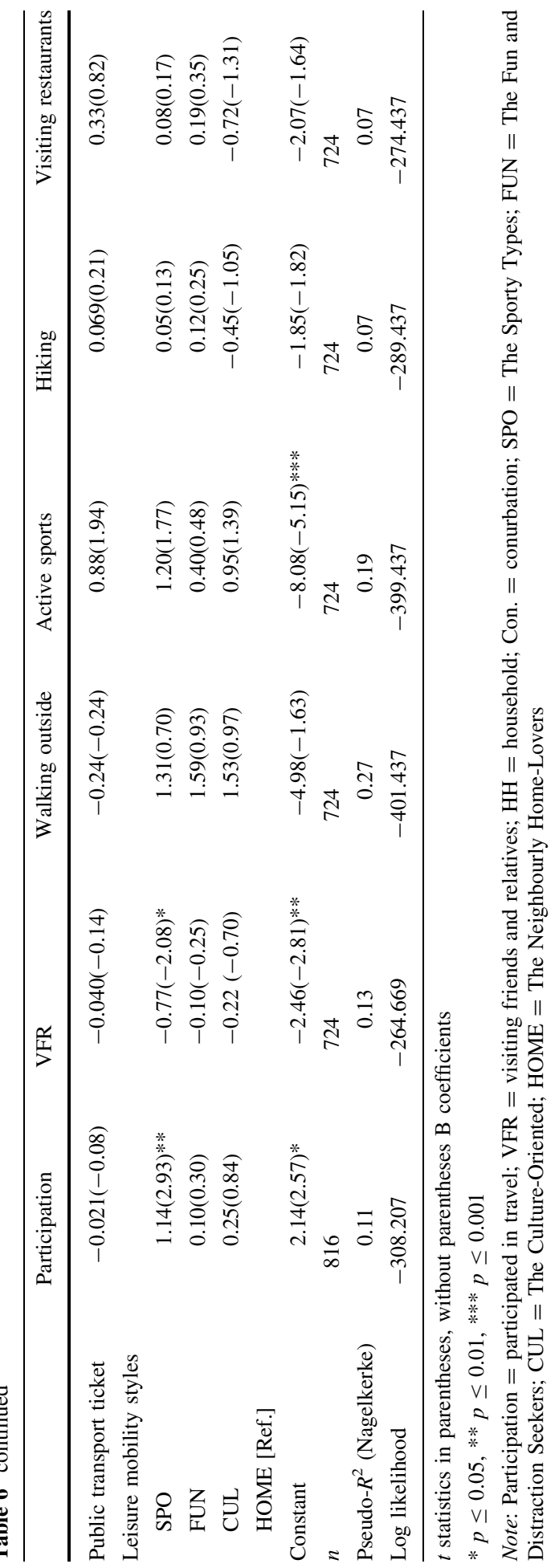


predict bicycle-share against trips and car-share against trips show a relatively high degree of explanatory variance. For all models, we detect a significant impact of leisure mobility styles on the selected travel key figures. For bicycle-share against trips, we transfer the data using the natural logarithm to achieve a better normal distribution of the residuals. Since there is no value for the logarithm of ' 0 ', we have only a sub-sample that includes people who participated in bicycle travel. Here, the leisure mobility styles turn out to have the biggest impact in terms of the standardised beta coefficients. In this model, bicycle-share against trips is highest for people in the lowest income class, who live in small households in the German-speaking part of Switzerland, and belong to the mobility style groups Sporty Types or Culture-Oriented, taking Neighbourly Home-Lovers as a reference category.

For car-share against trips, the highest share describes the following ideal type: fairly well-educated men, over the age of 29, living in smaller cities, a car in their household, and not in possession of any public transport season tickets. This profile features more strongly among Fun and Distraction Seekers (FUN) and less in the group of Culture-Oriented (CUL). This result is mirrored for car-share against travel distance, with the exception that conurbation size does not turn out to be significant.

Finally, the model for leisure travel distance produced the following ideal profile as having a high distance: men, mainly in the 30 to 59-year-old age group, a middle income of CHF 4,001 to 6,000, fewer under-18-year-olds in the household. Interestingly, they tend to live in larger households in a conurbation belt, and feature less strongly among the groups Fun and Distraction Seekers (FUN) and Culture-Oriented (CUL), according to the reference group Neighbourly Home-Lovers (HOME) (Table 7).

Overall, the multivariate analysis section reveals that leisure mobility styles only modestly correlate with activities undertaken on the sampled day. Concerning the variable selection search using a backward approach, it could be shown that leisure mobility style groups have a bigger effect. In fact, if other variables are controlled for, we still can detect significant influences between the leisure mobility styles regarding key figures for travel behaviour. Comparing the modelling results with models without lifestyle clusters, the explaining variance decreases on average by 10 per cent in cases where lifestyle clusters were significant. This indicates that the gains in explaining the variance are worthwhile but rather small. Likewise, it shows that explanations of a purely socio-demographic nature do not capture the whole picture with regard to horizontal stratification of the social fabric. The plurality of basic values leads to the emergence of differing value patterns in groups that have a similar socio-demographic structure. But, one has to ascertain that the various modelling approaches are adequate for different transportation research issues.

\section{Practical interventions}

To include lifestyles in models of travel behaviour is particularly useful to provide pointers for practical interventions, e.g., sociologically managed travel and spatial planning. The detailed results from the Swiss Travel Behaviour Microcensus have shown that leisure leads the field of travel purposes (ARE/BfS 2007). Policymakers and researchers want to know more about leisure travel with regard to greenhouse gas emissions from motorised leisure travel. Thus, knowledge of target-group-specific orientations and motivational factors is helpful in devising methods, and can also be used for 'social marketing' that influences behaviour in the direction of sustainability.

The approach outlined here offers an extension to the known planning instruments. Now, anyone wishing to influence leisure mobility and leisure travel can take all three 
Table 7 OLS-regression of selected travel key figures (Backward stepwise method)

\begin{tabular}{|c|c|c|c|c|}
\hline & $\begin{array}{l}\text { Bicycle share on } \\
\text { trips (LN) }\end{array}$ & Car share on trips & $\begin{array}{l}\text { Car share on travel } \\
\text { distance }\end{array}$ & $\begin{array}{l}\text { Travel distance for } \\
\text { leisure }\end{array}$ \\
\hline Men & - & $0.09(2.91)^{* *}$ & $0.08(2.32)^{*}$ & $0.10(2.69)^{* *}$ \\
\hline \multicolumn{5}{|l|}{ Age } \\
\hline $18-29$ & - & $-0.13(-3.64)^{* * *}$ & $-0.12(-3.23)^{* *}$ & - \\
\hline $30-59$ & - & - & - & $0.09(2.25)^{*}$ \\
\hline \multicolumn{5}{|l|}{$60+[$ Ref. $]$} \\
\hline \multicolumn{5}{|c|}{ Income (CHF) (per month) } \\
\hline $2,000-4,000$ & $0.25(2.33)^{* *}$ & - & - & - \\
\hline $4,001-6,000$ & - & - & - & $0.10(2.62)^{* *}$ \\
\hline $6,001-10,000$ & - & - & - & - \\
\hline \multicolumn{5}{|l|}{$10^{\prime} 000+$ [Ref.] } \\
\hline \multicolumn{5}{|l|}{ Education } \\
\hline Primary & - & $-0.09(-2.80)^{* *}$ & $-0.11(-3.02)^{* *}$ & - \\
\hline \multicolumn{5}{|l|}{ Tertiary [Ref.] } \\
\hline Kids in $\mathrm{HH}$ & - & - & - & $-0.14(-3.60)^{* * *}$ \\
\hline $\begin{array}{l}\text { More than } 3 \text { persons } \\
\text { in } \mathrm{HH}\end{array}$ & $-0.22(-2.11)^{*}$ & - & - & $0.16(4.12)^{* * *}$ \\
\hline Swiss-German & $0.25(2.19)^{*}$ & - & - & - \\
\hline \multicolumn{5}{|l|}{ Citizens in Conurbation } \\
\hline$+200,000$ & - & $-0.08(-2.30)^{*}$ & - & - \\
\hline \multicolumn{5}{|l|}{$\begin{array}{l}\text { Up to } 50,000+ \\
\text { [Ref.] }\end{array}$} \\
\hline $\begin{array}{l}\text { Lives in centre of } \\
\text { Con. }\end{array}$ & - & $-0.14(-4.16)^{* * *}$ & $-0.11(-3.21)^{* *}$ & $0.08(-2.15)^{*}$ \\
\hline Car-sharing member & - & - & - & - \\
\hline Car in household & - & $0.24(6.91)^{* * *}$ & $0.23(6.52) * * *$ & - \\
\hline $\begin{array}{l}\text { Public transport } \\
\text { seasonal ticket }\end{array}$ & - & $-0.27(-8.09)^{* * *}$ & $-0.24(-6.77)^{* * *}$ & - \\
\hline \multicolumn{5}{|l|}{ Leisure mobility styles } \\
\hline SPO & $0.44(2.42)^{* * *}$ & - & - & - \\
\hline FUN & - & $0.09(2.59)^{* *}$ & $0.09(2.44)^{*}$ & $-0.09(-2.27)^{*}$ \\
\hline CUL & $0.35(2.00)^{* *}$ & $-0.09(-2.63)^{* *}$ & $-0.09(-3.24)^{* *}$ & $-0.10(-2.49)^{*}$ \\
\hline \multicolumn{5}{|l|}{ HOME [Ref.] } \\
\hline$n$ & 73 & 724 & 724 & 724 \\
\hline Adj. $R^{2}$ & 0.18 & 0.29 & 0.26 & 0.06 \\
\hline
\end{tabular}

$t$ statistics in parentheses, without parentheses standardised B coefficients

$* p \leq 0.05, * * p \leq 0.01, * * * p \leq 0.001$

Note $: \mathrm{HH}=$ household; Con. = conurbation; $\mathrm{SPO}=$ The Sporty Types; FUN = The Fun and Distraction Seekers; CUL $=$ The Culture-Oriented; HOME $=$ The Neighbourly Home-Lovers

possible influences into consideration: spatial structural, social, and socio-cultural. As mobility style groups are barely addressed by public transport companies and administrative bodies in Switzerland, this approach could be a means of sensitising both to groupspecific measures. Firstly, to develop measures to influence the mobility orientation of distinct lifestyle groups and, second, to address the existing orientations (for an assesment 
of policy measures see Möser and Bamberg 2008). Based on the results of this project, we developed a list of group-specific recommendations and measures. The focus lies on the avoidance of car trips and a shift towards public transport, cycling and walking (for a list of measures see Ohnmacht et al. 2008b, pp. 112-116). A strategy have been developed for each of the leisure mobility styles presented. These approaches to service various leisure mobility styles in leisure time should be implemented in a broader framework of strategies, namely in transport policy for leisure travel and in transport policy in general. That these (often) so-called soft factors have an additional influence is recognised throughout nearly all levels of travel research. Concerning the work on social influence and in-group homogeneity, it could be ascertained that focusing on group dynamics within the same lifestyle group would be advantageous when planning sustainability measures (Páez and Scott 2007). For instance, combining tickets to cultural events with a free ticket for public transport. The popularity of this combination could be increased by interactions within the lifestyle group. To develop more specific measures, further research should develop survey designs that include social network data and lifestyle groups. Concerning social influence, on the basis of this bridge hypothesis, the empirical analysis would lead to the conclusion that practical interventions should focus more on travel mode and destination choice than on the influence of activity patterns.

\section{Concluding remarks}

In this paper we presented the idea of using leisure mobility styles as a means of expanding the approaches to travel behaviour research. Leisure mobility styles can be empirically constructed in a straightforward way using factor and cluster analysis, although the research design and survey process are rather costly and time-consuming. Moreover, the interpretation of the styles identified in this way require insight into the sociological structure of the research fields. We showed that for a better understanding of travel behaviour, it is fruitful to take orientation and attitude into consideration.

In summary, we could draw the following conclusions: Attitudinal, motivational and lifestyle dimensions can make a useful contribution to clarifying variance in travel behaviour. In our analysis, we could show how the data gained in the following categories contributes previously unobtainable information: participation in travel in general and for the purpose 'Visiting friends and relatives' in particular, bicycle- and car-share on trips, car-share for leisure travel, and travel distance for leisure. The inclusion of mobility styles may lead to more satisfactory ways of explaining travel behaviour, the main advantage being that one is taking the social realities of individualisation and pluralisation into account. The results indicate that lifestyle groupings can help clarify some aspects of behaviour, and while the contribution to increasing explanatory power may not be large, the significant results could be used for more targeted (and efficient) efforts to influence behaviour. Here, the issue of social influence with regard to the travellers' social network should be taken into account.

With regard to the Swiss Travel Behaviour Microcensus (Swiss National Travel Survey, see ARE/BfS 2007), it would be worth investigating if attitudinal items should also be taken up by the large travel surveys as a means for developing adequate lifestyle measures. In this context, one important research area can be defined as follows: This empirical analysis was based on cross-sectional data. Against the current background of demographic change, it is of major interest how individuals and households achieve membership or swap membership across the presented typologies over time. 
Acknowledgements The paper is based on a presentation at the Swiss Transportation Research Conference Annual Meeting (STRC). The authors wish to thank the anonymous reviewers for their constructive criticism. Their suggestions substantially improved the quality of the work. The research group also wishes to thank the Swiss Association of Transportation Engineers (SVI) for funding this research project. We especially want to thank Barbara Birzle-Harder (Heidelberg), Ingo Bald (Sociotrend, Leimen), Jutta Definer (the Institute for Social-Ecological Research, Frankfurt am Main), Jürg Stettler (Lucerne University of Applied Sciences and Arts) as well as Ueli Haefeli and Daniel Matti (Interface-Politikstudien, Lucerne) for the fruitful cooperation in this project.

\section{References}

Ajzen, I.: Understanding attitudes and predicting social behavior. Prentice-Hall, Englewood Cliffs, NJ (1980)

ARE/BfS.: Pendelverkehr - Neue Definition der Agglomerationen. Federal Office for Spatial Development and Swiss Federal Statistical Office, Bern and Neuenburg (2003)

ARE/BfS.: Mobilität in der Schweiz, Ergebnisse des Mikrozensus 2005 zum Verkehrsverhalten. Federal Office for Spatial Development and Swiss Federal Statistical Office, Bern and Neuenburg (2007)

Axhausen, K.W.: Activity space, biographies, social networks and their welfare gains and externalities: some hypotheses and empirical results. Mobilities 2, 15-36 (2007)

Axhausen, K.W.: Social networks, mobility biographies and travel: the survey challenges. Environ. Plan. B 35, 981-996 (2008)

Backhaus, K., Erichson, B., Plinke, W.: Multivariate Analysemethoden: Eine anwendungsorientierte Analysemethode. Springer, Berlin (2006)

Bamberg, S., Möser, G.: Twenty years after Hines, Hungerford, and Tomera: a new meta-analysis of psycho-social determinants of pro-environmental behaviour. J. Environ. Psychol. 27, 14-25 (2007)

Bamberg, S., Schmidt, A.: Auto oder Fahrrad? Empirischer Test einer Handlungstheorie zur Erklärung der Verkehrsmittelwahl. Kölner Zeitschrift für Soziologie und Sozialpsychologie 46, 80-102 (1994)

Bamberg, S., Hunecke, M., Blöbaum. A.: Social context, personal norms and the use of public transportation: two field studies. J. Environ. Psychol. 27, 190-203 (2007)

Banerjee, A., Ye, X., Pendyala, R.M.: Understanding travel time expenditures around the world: exploring the notion of a travel time frontier. Transportation 34, 51-65 (2007)

BAT-Freizeitforschungsinstitut.: Freizeit-Monitor 2004. Daten zur Freizeitforschung: Repräsentativbefragungen in Deutschland. B.A.T Freizeit-Forschungsinstitut, Hamburg (2004)

Bergman, M.: A theoretical note on the differences between attitudes, opinions, and values. Swiss Political Sci. Rev. 2, 81-93 (1998)

Bourdieu, P.: Distinction: A Social Critique of the Judgment of Taste. Harvard University Press, Harvard (1984)

Carrasco, J.A., Hogan, B., Wellman, B., Miller, E.J.: Collecting social network data to study social activitytravel behaviour: an egocentric approach. Paper presented at the 85th Annual Meeting of the Transportation Research Board, Washington, DC, January (2006)

Collantes, G.O., Mokhtarian, P.L.: Subjective assessment of personal mobility: What makes the differences between a little and a lot. Transp. Polcy 14, 181-192 (2007)

Dugundji, E.R., Walker, J.L.: Discete choice with social and spatial network interdependencies - an empirical example using mixed generalized extreme value models with field and panel effects. Transp. Res. Rec. 1921, 70-78 (2005)

Dugundji, E.R., Páez, A., Arentze, T.A.: Social networks, choices, mobility and travel. Environ. Plan. B 35, 956-960 (2008)

Erikson, R., Goldthorpe, J.H.: The Constant Flux. Clarendon, Oxford (1992)

Esser, H.: Why are bridge hypotheses necessary. In: Blossfeld, H.P., Prein, G. (eds.) Rational Choice Theory and Large-Scale Data Analysis, pp. 94-111. Westview Press, Boulder (1998)

Farber, S., Páez, A.: My car, my friends, and me: a preliminary analysis of automobility and social activities. J. Transp. Geogr. (in press). doi:10.1016/j.jtrangeo.2008.07.008

Giddens, A.: Entfesselte Welt: Wie die Globalisierung unser Leben verändert. Suhrkamp, Frankfurt/Main (2001)

Gliebe, J.P., Koppelman, F.S.: A model of joint activity participation between household members. Transportation 29, 49-72 (2002)

Götz, K., Jahn, T., Schultz, I.: Mobilitätsstile - ein sozial-ökologischer Untersuchungsansatz. Forschungsberichte Stadtverträgliche Mobilität Band 7, Frankfurt am Main (1997) 
Götz, K., Loose, W., Schmied, W., Schubert, S.: Mobilitätsstile in der Freizeit. Erich Schmidt Verlag, Berlin (2003)

Gunn, H.F.: Spatial and temporal transferability of relationships between travel demand, trip cost and travel time. Transp. Res. E 32, 163-189 (2001)

Hanson, S., Pratt, G.: Gender, Work, and Space. Routledge, London (1995)

Hägerstrand, T.: What about people in regional science? Pap. Reg. Sci. 24, 7-21 (1970)

Jahn, T., Wehling, P.: A multidimensional concept of mobility - a new approach to urban transportation research and planning. Paper presented at Urban Ecology, Berlin (1998)

Kitamura, R.: Life-style and travel demand. In: Transportation Research Board (ed.) A look ahead - Year 2020: Proceedings of the Conference on Long-Range Trends and Requirements for the Nation's Highway and Public Transit Systems, pp. 149-189. National Research Council, Washington D.C. (1988)

Konietzka, D. (ed.): Lebensstile im sozialstrukturellen Kontext. Westdeutscher Verlag, Opladen (1995)

Koppelman, F.S.: Travel-activity behavior in time and space: methods for representation and analysis. In: Nijkamp, P., Leitner, H., Wrigley, N. (eds.) Measuring the Unmeasurable, pp. 587-623. Martinus Nijhoff, The Hague (1983)

Kwan, M.P.: Gender, the home-work link, and space-time patterns of nonemployment activities. Econ. Geogr. 74, 370-394 (1999)

Lamprecht, M., Stamm, H.P.: Social stratification and the differentiation of life styles, social perception and attitudes in Switzerland. Paper presented at ISA XIV World Congress of Sociology at Research Committee Social Stratification, RC28, Montreal, Canada (1998)

Lanzendorf, M.: Mobility styles and travel behaviour: application of a lifestyle approach to leisure travel. Transp. Res. Rec. 1807,163-173 (2002)

Larsen, J., Urry, J., Axhausen, K.W.: Mobilities, networks, geographies. Asgate, Aldershot (2006)

Lücking, J., Meyrat-Schlee, E.: Perspektiven des Freizeitverkehrs Teil 1: Determinanten und Entwicklungen. Research Report, No. 41/92. Swiss Association of Transportation Engineers (SVI), St. Gall (1994)

Miller, E.J., Roorda, M.: Prototyp model of household activity-travel scheduling. Transp. Res. Rec. 1831, 114-121 (2003)

Möser, G., Bamberg, S.: The effectiveness of soft transport policy measures: a critical assessment and metaanalysis of empirical evidence. J. Environ. Psychol. 28, 10-26 (2008)

Ohnmacht, T.: Key characteristics of Swiss citizens in relation to social activity-travel behavior. Paper presented at the 88th Annual Meeting of the Transportation Research Board, Washington, D.C., January (2009)

Ohnmacht, T., Frei, A., Axhausen, K.W.: Mobilitätsbiografie und Netzwerkgeografie: Wessen soziales Netzwerk ist räumlich dispers? Swiss. J. Sociol. 31, 131-164 (2008a)

Ohnmacht, T., Götz, K., Haefeli, U., Deffner, J., Matti, D., Stettler, J., Grotrian, J.: Freizeitverkehr innerhalb von Agglomerationen. Research Report, No. 2004/074. Swiss Association of Transportation Engineers (SVI), St. Gall (2008b)

Ohnmacht, T., Götz, K., Schad, H., Haefeli, U., Stettler, J.: Mobility styles in leisure time - target groups for measures towards sustainable leisure travel in Swiss agglomerations. Paper presented at the 8th Swiss Transport Research Conference (STRC), Ascona, October (2008c)

Ohnmacht, T., Maksim, H., Bergman, M.: (eds.) Mobilities and inequality. Ashgate, Aldershot (2009)

Pas, E.I.: The effect of selected sociodemographic characteristics on daily travel-activity behavior. Environ. Plan. A 16, 571-581 (1994)

Páez, A.: Exploring contextual variations in land use and transport analysis using a probit model with geographical weights. J. Transp. Geogr. 14, 167-176 (2006)

Páez, A., Scott, J.: Social influence on travel behaviour: a simulation example of the decision to telecommute. Environ. Plan. A 39, 647-665 (2007)

Plickert, G., Côtè, R., Wellman, B.: It is not who you know, it is how you know them: who exchanges what with whom? Soc. Netw. 29, 405-429 (2007)

Plöger, W.: Sinus Sociovision: Die Sinus-Milieus in der Schweiz (2006). Available via http://www.thchur. ch/ressourcen/download/20070620064546.pdf. Accessed 1 Dec 2008

Root, A., Schintler, L., Button, K.J.: Women, travel and the idea of 'sutainable transport'. Transp. Rev. 20, 369-383 (2000)

Salomon, I.: Life styles - a broader perspective on travel behaviour. In: Carpenter, S.M., Jones, P.M. (eds.) Recent Advances in Travel Demand Analysis, pp. 290-310. Gower, Aldershot (1983)

Salomon, I., Ben-Akiva, M.E.: The use of life-style concept in travel demand models. Environ. Plan. A 15, 623-638 (1983) 
Schad, H., Ohnmacht, T., Sonderegger, R., Sauter, D., Stettler, J.: Gebaute Umwelt und körperliche Aktivität. Analysen und Empfehlungen für die Schweiz. Research Report, Swiss research concept "Sports and physical activity" (2004-2007), Lucerne University of Applied Sciences and Arts, Lucerne (2008)

Scheiner, J.: Mobility biographies: elements of a biographical theory of travel demand. Erdkunde 61, 161173 (2007)

Scheiner, J., Holz-Rau, C.: Travel mode choice: affected by objective or subjective determinants? Transportation 34, 487-512 (2007)

Schlich, R., Schönfelder, S., Hanson, S., Axhausen, K.W.: The structures of leisure travel: Temporal and spatial variability. Transp. Rev. 24, 219-228 (2004)

Schwanen, T., Ettema, D.F., Timmermans, H.J.P.: If you pick up the children, I'll do the groceries: Spatial differences in between-partner interactions in out-of-home household activities. Environ. Plan. A 39, 2754-2773 (2007)

Schwanen, T., Ettema, D.F., Timmermans, H.J.P.: Exploring the juggling of responsibilities with space-time accesibility analysis. Urban Geogr. 29, 556-580 (2008)

Scott, J., Kanaroglou, P.S.: An activity-episode generation model that captures interactions between houeshold heads: development and empirical analysis. Transp. Res. B 36, 875-896 (2002)

Walker, J.L., Li, J.: Latent lifestyles preferences and household location decisions. J. Geogr. Syst. 9, 77-101 (2007)

\section{Author Biographies}

Timo Ohnmacht is a sociologist, research officer at the Lucerne University of Applied Sciences and Arts and a doctoral student at the University of Basle, Department of Sociology, Switzerland. His research focus is on the interrelationships of mobilities, inequality, and modernity as well as leisure and tourism travel.

Konrad Götz is a sociologist at the Institute for Social-Ecological Research (ISOE), Frankfurt. He is an expert for empirical studies about lifestyle and mobility. His doctoral dissertation was published as "Leisure Time Mobility in Everyday Life". Before starting at ISOE he worked as a market researcher at the Sinus Institute in Heidelberg.

Helmut Schad is a geographer, lecturer and researcher at the Lucerne University of Applied Sciences and Arts, working on travel behaviour and mobility management. 